\title{
Preface: 11th Plinius Conference on Mediterranean Storms
}

\author{
M.-C. Llasat ${ }^{1}$, G. Boni ${ }^{2,3}$, R. Deidda ${ }^{4}$, A. Mugnai $^{5}$, and J. Salat ${ }^{6}$ \\ ${ }^{1}$ Departament d'Astronomia i Meteorologia, Universitat de Barcelona, Barcelona, Spain \\ ${ }^{2}$ CIMA Research Foundation, Savona, Italy \\ ${ }^{3}$ Dipartimento di Informatica, Bioingegneria, Robotica ed Ingegneria dei Sistemi, Università di Genova, Genova, Italy \\ ${ }^{4}$ Dipartamento di Ingegneria Civile, Ambientale e Architettura, Università di Cagliari, Cagliari, Italy \\ ${ }^{5}$ Istituto di Scienze dell' Atmosfera e del Clima, Consiglio Nazionale delle Ricerche, Rome, Italy \\ ${ }^{6}$ Institut de Ciències del Mar (CSIC), Barcelona, Spain
}

Correspondence to: M.-C. Llasat (carmell@am.ub.es)

\section{Introduction}

The EGU Plinius Conference on Mediterranean Storms was established in 1999 within the framework of the Interdisciplinary Working Group on Natural Hazards (IWG-NH) of the former European Geophysical Society (EGS) - since 2002, European Geosciences Union (EGU). Since its advent, the Plinius Conference series has provided a crucial interdisciplinary forum for improving our understanding of hazardous storms over the Mediterranean basin that are capable of producing strong winds, heavy rains, explosive landslides, devastating flash floods and other related extremes. Given the progress both in the understanding of many of the basic scientific aspects of the triggering, growth, maintenance, and physical impacts of Mediterranean storms, as well as in the model prediction concerning storm life cycles and their hazardous impacts, the 11th Plinius Conference encouraged an even greater interdisciplinary participation than in previous editions. This was achieved by continuing to reach out to scientific experts in the fields of meteorology, climatology, hydrology, and geomorphology, as well as extending the reach into the disciplines of oceanography, sociology, economics, engineering, and the government management sector.

In total 211 contributions were submitted, and more than 150 scientists attended the conference. Scientific topics encompassed a wide range and included the following: (i) the nature and physical processes of extreme events; (ii) possible changes in storm behavior resulting from anticipated changes in climate; (iii) advanced techniques to observe, monitor and forecast hazardous storms; (iv) relationships between atmospheric and surface processes for both land and sea situations, with particular emphasis on the effects of coupled processes in generating damaging floods and landslides; and (v) socioeconomic implications of hazardous storms, risk mitigation and resilience in the framework of sustainable development. Consequently, the conference included 12 topics that will be introduced along with this preface to the special issue.

This conference also provided a meeting venue for various ongoing international initiatives and projects that seek better ways to investigate or cope with Mediterranean storms: the open session of the European FLASH project (Observations, Analysis and Modeling of Lightning Activity in Thunderstorms, for use in Short Term Forecasting of Flash Floods); the joint MedCLIVAR (Mediterranean CLImate VARiability and Predictability), HyMeX (HYdrological cycle in Mediterranean EXperiment) and MEDFRIEND (Mediterranean Flow Regimes from International Experimental and Network Data) meeting concerning collection of precipitation data associated with Mediterranean storms; and the annual meeting of the MEDEX Project (MEDiterranean EXperiment) of the World Meteorological Organization (WMO).

The conference was closed with a round table that was attended by several participants, who drew a series of conclusions and recommendations with special emphasis on the potential synergies among the different disciplines. These conclusions are summarized within the various sections of this introductory paper, which contains a synthesis of the 38 papers included in this NHESS special issue, as well as of some papers published in the joint special issue of "Advances in Geosciences" (ADGEO) relative to this conference (Llasat et al., 2010a). 


\section{Societal impacts, risk management, responses, and education}

Three main focal points were identified in this session: (1) to increase public awareness to understand risk, vulnerability and disaster reduction globally; (2) to stimulate the interdisciplinary and inter-sectorial partnerships, including the expansion of risk reduction networks; and (3) to improve scientific knowledge about disaster reduction. Noteworthy is that while point 3 was treated by Pelosini et al. (2011), the paper of Lara et al. (2010) mainly deals with the first point. In summary, after analyzing three case studies in Costa Brava region (Spain), the latter paper concludes that flood awareness and preparedness are mainly related to the degree of social involvement with the activities of the local community. By the same token, modification of human activities should be considered as an important task for the improvement of flood management. Focusing on another Spanish region (in this case, the coast of Alicante), Olcina Cantos et al. (2010) analyze the increased exposure and vulnerability to floods as a result of a major urban occupation of areas that are subject to this hazard, in spite of the existence of flood risk prevention plans. Survey-based research in the areas affected by the most recent episodes reveals a lack of awareness for a large portion of the population, which is particularly evident for the seasonal inhabitants or residents who have not lived in the area for very long. This factor, which affects the major part of the Spanish Mediterranean coast, is important given the notable increase in the coastal towns' population of retired residents from western and northern Europe. Remarkably, the paper by Llasat et al. (2010b), who perform a detailed analysis of the evolution of flash floods in Catalonia (NE of Spain) for the period 1982-2007, corroborates these results by showing the major role played by temporal changes and evolution in exposition and vulnerability factors. In particular, these authors find a flash-flood impact increase in summer and early autumn, which is mainly due to inter-annual and intra-annual changes in population density on the Catalan coast.

The conference also emphasized some important questions for the future that can still be considered as major challenges. Among them, the following ones are most remarkable: how should uncertainty be communicated to citizens and policymakers? Is it the responsibility of scientists to communicate risk, or should policymakers be able to understand the scientific implications? What are the legal responsibilities of scientists in terms of natural hazards? What is the chain of responsibilities? A stronger collaboration between experts and administration is needed, but how? A common language is needed, but is it possible? How could public awareness be increased? And are citizens really interested in this? The paper by Altamura et al. (2011), together with a related paper (Llasat and Siccardi, 2010) presented in a previous Plinius Conference (see Mugnai et al., 2010), offers an innovative interdisciplinary approach to address these questions, which have become particularly remarkable and urgent after the L'Aquila (Italy) earthquake in 2009 and the flash floods in Genoa (Italy) in November 2011, when some scientists and civil protection members were charged and found guilty. Specifically, both papers analyze the Civil Protection decisions resulting from short-term forecasts of hazardous events, taking into account both the improvement of numerical weather prediction (NWP) models and the associated uncertainty. In particular, the paper of Altamura et al. (2011), which also considers the trial following the violent meteorological event of Vibo Valentia (Italy) in 2006, maintains that the process of "overcriminalization" of Civil Protection is currently increasing the number of false alerts with the consequent effect of weakening alert perception and response by the citizenship.

Meteorological services play a key role in disaster mitigation by first generating weather forecasting and warnings, and then monitoring alert situations. In addition, they play an important role in the recovery tasks by providing information to citizens and insurance companies. In this regard, Amaro et al. (2010) present an innovative approach to evaluate the societal impact of high-impact weather events. Specifically, the paper shows the results from a pilot study, carried out in accordance with the guidelines proposed by the Social Impact Research Group of MEDEX, which analyzes the requests received by the Meteorological Services of the Balearic Islands and Catalonia (Spain) in relation to the damages caused by weather events. As a result, the authors suggest some general and suitable criteria about how to analyze this kind of requests, and how to use them to evaluate the impact of hazardous events on society. In particular, they propose a new index to evaluate the social impact, which involves the maximum precipitation and the percentage of population within a region with more than $60 \mathrm{~mm}$ recorded. While this new index provides a good approach, other factors like length of the event, vulnerability, intensity and synergy with other simultaneous hazards should be also considered in future research.

\section{Climate change impacts on Mediterranean storms}

In the recent years it has become more and more important to study and evaluate the impact of climate change on hazardous events and their potential risks. These analyses, however, constitute a major challenge due to the great amount of factors that are implied. For instance, factors like changes in vulnerability and mitigation measures, which have been already introduced in the previous section, should be taken into account when the evolution of natural risks is considered. As a result, these assessment studies may be highly dependent on the methodologies and data that are used to analyze trends and anomalies, while analyses for different time periods may give different results and lead to ambiguous conclusions. This is the case for the papers by Neppel et al. (2011), which deals with a multivariate regional test for 
the detection of trends in extreme rainfall, and by Ortego et al. (2010), which focuses on the application of the Bayesian analysis to detect potential trends in daily rainfall series.

Quite analogously, the results of synoptic climatology studies should be carefully verified as similar results may be found by other studies for completely different situations, thus leading to uncertain conclusions. Furthermore, climatological studies should be based on a large number of stations with reliable time series, while the spatial dependence among them should be taken into account. The paper by Caloiero et al. (2011) is a good example of rainfall trend analysis using a large number of stations (70 rain gauges covering five regions in southern Italy) and a homogeneous series over a long period (1916-2003). The results show significant negative trends for annual and winter aggregations in most part of the series, as well as a strong correlation between precipitation and teleconnection pattern indexes - mainly, the North Atlantic Oscillation (NAO) and Mediterranean Circulation indexes - for this region, especially in winter and on the Tyrrhenian side of the Campania region.

In addition, other factors like changes in perception and observation can make it difficult to perform the assessment. This is the case for the paper by Gayà et al. (2011) for which a climatology of tornadoes and waterspouts in Catalonia for the period 1950-2009 was developed after a rigorous validation process, identifying 97 tornadoes and 62 waterspouts. The authors show the highest concentration of these phenomena from August to October and the highest density in the heavily populated coastal areas, like for the flash-flood case presented by Llasat et al. (2010b). Although the temporal evolution shows a growing positive trend, this is likely more closely linked to an increase in exposure, observation and perception rather than a real climatic trend.

Two papers (Casas-Prat and Sierra, 2010 and Rasilla Álvarez and García Codron, 2011), which are also discussed in Sect. 12, deal with changes in sea wave storminess along the coasts of Spain. Casas-Prat and Sierra (2010) present an analysis of the trend of wave storminess for the Catalonia region, which offers the advantage of being focused on the hazard aspects, avoiding the difficulty of dealing with mixed societal and natural risks. Specifically, long-term alterations in the wave storminess pattern of the Catalan coast are analyzed in terms of wave energy content and wave direction, on the basis of wave hindcast data for the period 1958-2001. Although no significant temporal trends are found for annual mean and maximum storm energy, a remarkable increase in the storm energy of events from the south is found, which is partly due to a rise in the annual percentage and magnitude of such storms. This result highlights the importance of analyzing changes in wave direction in the study of potential impacts of climate change. These changes can affect the sea agitation inside ports (the paper analyzes the case of the Port of Tarragona, one of the most important in the western Mediterranean) as well as the dynamic of some beaches, and, consequently, the moored vessels and port operations, the port efficiency, and the commercial, transport, and leisure activities.

Rasilla Álvarez and García Codron (2011) study the evolution of storminess along the northern coast of the Iberian Peninsula through the calculation of an index, the Total Water Level, based on tide gauge and buoy data, as well as on hindcast data (the so-called SIMAR 44 database) for the period 1958-2001. As it is the same period analyzed by the previous paper, it is possible to perform a comparison between the effects on the northeastern (Mediterranean Sea) and northern (Atlantic Ocean) coasts. In the latter case, the authors find that while local atmospheric conditions seem to be evolving towards less storminess (i.e., a reduction of the number and strength of the Atlantic storms), the exposure of the northern coast to the increasing frequency and strength of distant disturbances crossing the North Atlantic has compensated this decrease, so that no global trend is found.

The paper of Casas-Prat and Serra (2010) is also a good example of other important challenges associated with climate change scenarios, which have become major conclusions of this session: the uncertainty and the reliability. Specifically, the choice of a temporal model for the extrapolation of future projections produces a certain inherent uncertainty in the results, which is very difficult to evaluate. In addition, in order to build more robust future predictions, the reliability of the simulated climate forcing should be verified beyond the observed mean climatology. For example, a comparison with an observational data set should also focus on the statistical features of alternating extreme value periods.

De Lima et al. (2010) present a comprehensive and indepth discussion of the long-term behavior of annual and monthly precipitation over the Portuguese territory, based on 14 precipitation data sets from mainland Portugal and the Portuguese North Atlantic archipelagos of Madeira and Azores that span periods ranging between 88 and $145 \mathrm{yr}$. Specifically, the study focuses on the presence of linear monotonic trends in the temporal structure of precipitation over the record period and over sub-periods (i.e., partial trends). While no clear trend is found for the annual precipitation over the full record period, the analyses of the $50 \mathrm{yr}$ moving averages of annual precipitation reveal an increase over time, in the recent past, for many of the series. In addition, the partial trends in the time series show a sequence of alternating periods of decreasing and increasing annual and monthly precipitation - which demonstrates that the analyses of short precipitation records consisting of only a few decades should be considered cautiously for they can be biased by the period studied.

Two final conclusions of this session were that our studies on future climate, which mainly deal with the temperature and precipitation regimes as well as their extreme values by the end of the century, should (a) take into account new parameters (such as soil moisture, vegetation dynamics, etc.), and (b) examine in detail the transitional seasons, spring and 
summer, in addition to winter and summer, which usually attract the interest of researchers.

\section{Paleofloods and historical information concerning damaging Mediterranean storms}

This session addressed the use of proxy data to enlarge the record period of extreme events by means of a multidisciplinary approach that takes into account several types of data (documentary sources, natural proxies, and so on). The main research objectives identified in this session, which are still important challenges, were the following: (a) to perform detailed analyses of old extreme events; (b) to improve the uncertainty analyses concerning natural hazards by using additional paleo- and historical information; and (c) to analyze the variability of extreme events amongst large periods characterized by different climatic conditions.

The paper presented by Balasch et al. (2010) is an example of objective (a). The paper focuses on the Santa Tecla flash flood event that occurred in Catalonia (NE Spain) in 1874. Thanks to flood marks and written accounts and by iteratively using hydraulic and hydrological modeling, the authors are able to reconstruct the flood in some affected basins and to estimate the magnitude range of the rainstorm that caused the flash flood. Noteworthy is that this kind of research is crucial to improve the flood probability analysis, especially in ungauged basins or referring to long return periods.

\section{Remote sensing of storms}

Ten oral presentations (four of which are solicited) and eleven poster presentations were given at the conference within this topic. Although only one paper (Dietrich et al., 2011) was thereafter published in the Plinius-11 NHESS special issue, while none was submitted to the ADGEO special issue, we can say that this session was quite successful as it was characterized by a variety of high-quality presentations that covered several different aspects of remote sensing of precipitating storms - from the description of already operational or proposed ground-based and space-borne new technological systems, to the discussion of advanced retrieval methods and finally to the presentation of multi-sensor observations and analyses of heavy storms.

In particular, Dietrich et al. (2011) describe a new multisensor morphing technique - which they call lightning-based precipitation evolving technique (L-PET) - for continuously monitoring convective rain cells by combining lightning measurements from ground-based networks (such as ZEUS or LINET) and multi-frequency brightness temperature measurements taken by the AMSU/MHS microwave radiometer suites on board NOAA/EUMETSAT low Earth orbiting (LEO) operational satellites. Specifically, the proposed technique exploits the lightning data to propagate forward in time the rain fields estimated from the last available microwave observations from space. Thus, the L-PET technique may be useful not only for real-time monitoring but also for the nowcasting of convective cloud systems. Finally, the authors present a successful preliminary assessment of their technique for two convective storms that occurred over the island of Sicily, in southern Italy, and over central Europe.

The main conclusion of this session was that a variety of technology sources and associated retrieval techniques are presently used, and several more are under development and/or planned for the near future, to monitor precipitation within the Mediterranean basin in consideration of societal impacts vis-à-vis rainfall location, duration, intensity, and propagation. These sources include the following: (1) stand-alone radars and radar networks operating at different wavelengths (i.e., C-, X-, Ku- and Ka-bands); (2) multifrequency microwave and infrared radiometers (such as SSMIS, AMSU/MHS, or SEVIRI) on board operational and research low-Earth orbiting and geosynchronous satellites, as well as the radar - microwave radiometer payload suites of the NASA-JAXA space observatories dedicated to precipitation observation (i.e., the Tropical Rainfall Measuring Mission (TRMM), which has been operating since 1997, and the Core Satellite of the international Global Precipitation Measurement (GPM) mission, which will be launched in 2014); (3) ground-based lightning discharge detection networks (such as ZEUS and LINET); and (4) microwave cellphone communication networks. At the same time, it was stressed that the different retrieval uncertainties related to the various measurement technologies and associated retrieval techniques should be carefully assessed for they affect both the meteorological and the hydrological applications.

Evidently, the development of an integrated observation system would represent the optimal approach for making use of these technologies for monitoring heavy storms and thus for mitigating societal impacts within the Mediterranean basin, recognizing that there are different capabilities and data access policies across and within the national boundaries. Nevertheless, a question arises that needs to be carefully examined and answered in this context: given the heterogeneity of the precipitation monitoring capabilities within the Mediterranean basin, what is the most cost-effective method of combining the existing capabilities into an effective system for protecting society from the hazards of precipitating storms?

\section{Storm processes}

This session focused on the dynamics and scale interaction processes, thermodynamics, microphysics, electrification and boundary layer processes driving storm systems in the Mediterranean region. The contributions included theoretical, observational and numerical studies of the processes involved in the genesis, intensification, track and decay of these storms. 
The presentations given in this session have made it possible to draw the some conclusions. (1) The association of cyclonic storms formed over the Mediterranean region, including the so-called "medicanes", with upper level PV (potential vorticity) anomalies and thermal and humidity structures, is ubiquitous. This suggests an important role of baroclinic processes in the dynamical construction of these storms, which is not typical of purely tropical storms and perhaps more consistent with sub-tropical storms or polar lows. (2) The HRH (High-Resolution Hurricane) Test, completed in the USA, helps resolve issues regarding the limits of model predictability as resolution is increased. Results suggest that probabilistic forecasting involving ensembles is needed for subsynoptic-scale weather governed by flow features having lifetimes and space scales not resolved by the observation network or lifetime scales less than the forecast period. (3) Basic research, which is presently carried out, is leading to a better understanding of the relationships between atmospheric structure and structure, intensity and positioning of convective-orographic rain.

The papers included in this special issue concern some of the topics covered in the session. Duffourg and Ducrocq (2011) investigate the origin of the moisture feeding the heavy precipitation events (HPEs) over southeastern France. The study is of general importance since HPEs are the main cause of flood-related damages and casualties throughout the Mediterranean. By combining highresolution and large-scale meteorological simulations, the authors identify the feeding mechanism of HPEs and the sources where the feeding (moisture) comes from. Results show that HPEs are fed by a south-southwesterly to easterly low-level moist flow. The low-level feeding flow is provided in the short term by evaporation from the Mediterranean Sea and, in the longer period, by transport from remote sources in the lower half of the troposphere. The paper provides a first estimation of the quantitative relations between the two contributions of moisture, which are inferred from the water vapor mixing ratio evolution along some air parcel trajectories. Usually, the Mediterranean Sea results in being the most important moisture source.

The paper by Müller and Kaspar (2011) concerns a topic similar to the previous one, focusing on intense precipitation events in the southeastern Alps. Specifically, the authors find that the climatology of extreme runoff events in some mountain river basins (Mura, Drava and Sava) in the southeastern Alps is strongly correlated to the climatology of intense atmospheric moisture fluxes.

The third paper included in this special issue (Martín et al., 2011) focuses on extreme wind gusts. By using singular value decomposition analysis, the authors investigate the springtime relationships between wind gusts that occur over the Iberian Peninsula and the monthly averaged sea-level pressure field over the North Atlantic. They find two main co-variability modes that are associated with large-scale features of the atmospheric circulation over the North Atlantic: the first mode links above-normal wind gusts and the Scandinavian pattern, while the second mode correlates maximum wind speeds with the NAO pattern.

During the discussions following the presentations, a specific issue to be considered by future research on the subject has emerged: it is still poorly understood how Mediterranean cyclones, including medicanes, with their specific dynamical and thermodynamical construction and genesis processes, fit into the continuum of synoptic and mesoscale cyclones ranging from mid-latitude baroclinic cyclones to tropical warmcore cyclones.

\section{Mesoscale modeling and data assimilation}

The performance of mesoscale models can be strongly affected by the parameterization schemes that are adopted. Some parameterizations can perform better than others depending on geographic and topographic conditions, model grid resolution, synoptic conditions and storm types. This session was devoted to presentations dealing, within this framework, with the meteorological modeling of mesoscale phenomena that affect the Mediterranean area and are associated with severe weather and storms. Thus, contributions ranged from sensitivity and verification studies of mesoscale models and parameterization schemes in reproducing wind and rainfall conditions in extreme Mediterranean storms, to the assessment of climate change impacts.

Koletsis et al. (2010) evaluate the performance of the nonhydrostatic MM5 model with $1 \mathrm{~km}$ horizontal resolution in reproducing strong northerly wind gusts in a narrow gap located between two high mountains (Lefka Ori and Idi) on the island of Crete. Their conclusions support the potential of mesoscale models to simulate realistically strong wind fields in elevated gaps with complex topography.

Mazarakis et al. (2011) analyze the sensitivity of quantitative precipitation forecast to various modifications of the Kain-Fritsch (KF) convective parameterization scheme. Specifically, these authors apply the MM5 model, with five different modifications of the KF scheme, to 20 selected cases in Greece characterized by different precipitation types, and evaluate the corresponding skills against raingauge measurements.

Another study on the sensitivity of a mesoscale model (the Regional Atmospheric Modeling System, RAMS) to different convective parameterization schemes was presented by Gómez et al. (2011), who compare the performances of the $\mathrm{KF}$ and Kuo schemes for the Iberian Peninsula. On the basis of several tests conducted using different grids and evaluated with different performance metrics, these authors conclude that the Kuo convective scheme generally performs better than the KF one.

Katsafados et al. (2011) test the sensitivity of a limited area model to different sea surface temperature (SST) products (i.e., climatological, gridded analyses, satellite-derived 
and high-resolution re-analysis SSTs) in reproducing a deep storm that occurred on 21-22 January 2004 along the coast of the northern Aegean Sea (eastern Mediterranean). They conclude that the system was mainly controlled by the upper air atmospheric conditions and that the different SST products have a limited impact on the intensity and location of the modeled storm.

Finally, Groppelli et al. (2011) focus on the coupling of a hydrological model with selected global climate models (PCM, CCSM3, HadCM3), based on precipitation and temperature downscaling tools, to investigate the future hydrological cycle (2045-2054) of the snow-fed Oglio Alpine watershed in northern Italy under different climate change scenarios.

\section{Hydrological processes and modeling}

The development of any hydrological model requires continuous testing and verification of its dynamics and parameterizations. In predicting the impact of severe storms, the hydrological component has a fundamental role and must be correctly interfaced with the meteorological or climatological forcing. In addition, there is a need to identify properly the different sources of uncertainty and errors in order to improve the accuracy of the overall process. On the other hand, statistically based approaches are used to assess flood quantiles in ungauged catchments to design civil protection works correctly. Within this framework, the session focused on research, application advances, and future needs in the understanding and modeling of surface and near-surface hydrological processes, with special emphasis on the capability of describing extreme events. Presentations also dealt with uncertainty in hydrological modeling, hydrological ensemble systems, and prediction of extreme floods in poorly monitored basins. Some contributions presented results from physically based hydrological models, while others were based on statistical approaches.

Roux et al. (2011) present a spatially distributed and physically based hydrological model (MARINE), which is particularly parsimonious and requires only the calibration of four parameters. The authors also show the results of a sensitivity analysis based on Monte Carlo simulations and analyze a model application to the Gardon d'Anduze catchment in southern France.

Mascaro et al. (2010) analyze the impact of several physical features on the accuracy of ensemble streamflow forecasts (ESFs). The simulation setting uses rainfall data estimated by the Next-Generation Radar (NEXRAD) network, the Space-Time RAINfall (STRAIN) multifractal downscaling model, and the TIN-based Real-time Integrated Basin Simulator (tRIBS) distributed and physically based hydrological model. Their results highlight the dependence of ESF dispersion on basin area, land cover, soil texture, morphometric features and antecedent rainfall.
Turning to the statistically based approaches, Sirangelo et al. (2011) present a stochastic model based on a nonhomogeneous Poisson process able to reproduce the seasonal variability of daily rainfall occurrences. The model is then applied to a set of rain gauges in southern Italy. The results support the conclusion that the frequency of occurrence, needed to characterize the Poisson process, can be satisfactorily modeled by 2-harmonic Fourier series.

Terranova and Iaquinta (2011) present a new criterion for the classification of standardized rainfall profiles (SRPs) and test their approach on more than 45000 rainfall events collected by 155 rain gauges in Calabria (southern Italy) with 5 min resolution. The authors show how their criterion can improve Huff's approach in discriminating erosive rainfall events.

Iacobellis et al. (2011) present a regional probabilistic model (two-component IF model, TCIF) for the estimation of flood quantiles, which accounts for two different threshold mechanisms associated with ordinary and extraordinary flood events. By using yearly maximum flood records from 33 gauges in southern Italy, the authors investigate possible relationships between model parameters and river basin descriptors (e.g., related to climate geomorphology, vegetation coverage, soil type and permeability, etc.) with the aim to provide an operative tool for flood estimation in ungauged basins.

Within the same line of research, Portoghese et al. (2011) face the problem of coupling hydrological models with climate models predictions for the assessment of climate change impacts on hydrological processes. Specifically, they present a stochastic scheme for precipitation bias correction at the regional climate model cell scale, which produces a realistic representation of the daily rainfall intermittency and precipitation depths.

Finally, Rianna et al. (2011) present a statistical analysis of daily flows, focusing on river basins with intermittent runoff. Their study comprises two components: (a) a statistical framework, based on a stochastic index approach, for constructing flow-duration curves in the presence of zero flows; and (b) a regionalization approach, involving the investigation of possible correlations between hydrological and geomorphological variables, accompanied by a cluster analysis for identifying homogenous regions. The methodology is then tested in a number of hydrometric stations in central Italy.

In summary the session offered a very stimulating forum to discuss process conceptualization and modeling approaches at different spatial and temporal scales, including model parameter identification and calibration, as well as sensitivity analyses to parameterization and scales of process representation. 


\section{Flash floods: from observations to forecasting}

In the Mediterranean region, flash floods produced by extreme rainfall are among the risks that endanger human lives the most. There is extensive literature on the ground effects of this type of events (see Sect. 3), but observation and forecasting of this type of events is quite difficult due to the small spatial scale and the very rapid temporal dynamics.

In particular, the difficulty in obtaining prompt and detailed observation generates a lack of knowledge of the physical causes of these phenomena and produces large uncertainties in their forecasts. Nevertheless, the new observation technologies, which are based on new and/or planned satellite, weather radar, and dense real-time observational networks (see Sect. 5), can provide an important contribution to the knowledge of the physics of extreme rainfall events that produce flash floods in the Mediterranean and their numerical modeling for prediction purposes.

Observations provided by the modern sensors can be used in different ways: (1) to build operating systems that receive input from a variety of data sources available today and then provide reliable space-time representations of the observed phenomena and predictions; (2) to reduce the uncertainty in the statistical evaluation of the hazards associated with flash floods (see also Sect. 8); and (3) to understand the underlying physics and reduce the uncertainty of predictive models through a better representation of the phenomena. The conference session on flash floods was dedicated to presentations addressing the first and third topics.

Presentations of the last type were also sub-divided into two categories, both aiming at the understanding of the physical causes of flash floods, but characterized by different approaches. Specifically, some presentations made use of massive data analysis on a large number of extreme events to identify the common factors that have to be better represented in operational model applications. Other presentations focused more on the interpretation of the observations through simple physically based models in order to understand the underlying physics and the causes of uncertainty in operational modeling better.

Only one paper of this session is included in this NHESS special issue. It does not give a global representation of the oral and poster contributions to the conference. The paper, by Montesarchio et al. (2011), presents an operational warning system based on rainfall thresholds, which makes use of weather radar data. The authors' objective is to build a simplified, reliable, rapid and objective system for issuing shortterm alerts. The critical rainfall threshold values are evaluated by minimizing a utility function based on the informative entropy concept and by using a simulation approach based on radar data. The utility function also includes subjective evaluations based on the perception of risk by the decision maker. However, the authors point out that the best performance is obtained when the use of such subjective evaluations is minimized. The paper also shows an attempt to quantify the overall uncertainty associated with the evaluation of the threshold values, which needs further investigation, as stated by the authors themselves.

Other papers presented in this session have been published in the related ADGEO special issue, also dedicated to the conference, to which we refer for further details. The paper by Camarasa Belmonte et al. (2010) presents an attempt to use time series of rainfall observations at different time resolutions to define rainfall thresholds for operational alert systems at the regional scale. Lambert et al. (2011) present the CORSICA project, which aims at the implementation of a multi-site instrumented platform located on the island of Corsica for intensive monitoring and improvement of the understanding of the underlying physics of extreme events and other weather- and marine-related processes.

The main conclusion of this session was a recommendation that future conferences should focus more on the understanding of the physics of flash-flood-related processes, as well as on the sources of uncertainty in forecasting. In addition, it was pointed out that there is a need to highlight better what is still poorly known or unknown about flash floods in the Mediterranean environment, and thus a need to indicate priorities in future lines of research.

\section{Nowcasting}

Ten presentations (six of which are oral, one solicited) were given at the conference within this topic. Two papers (Atencia et al., 2010; Rigo et al., 2010) were thereafter published in the Plinius-11 NHESS special issue, and another one (Terradellas and Téllez, 2010) in the ADGEO special issue.

Atencia et al. (2010) present an attempt to improve quantitative precipitation forecasts (QPFs) by blending different sources of information, including both numerical weather prediction (NWP) model outputs and weather radar observations processed to obtain a nowcasting of the rainfall field. The technique of blending varies the weight of the different sources of information as a function of forecast lead time, maximizing the importance of the weather-radar-based nowcasting for short lead times and increasing gradually the importance of the NWP for long lead times. Currently, the Meteorological Service of Catalonia (SMC) uses the system operationally. The authors conclude that the blending technique (especially the spatial one) is a suitable approach to improve the QPF in the first hours of observation.

Rigo et al. (2010) present a nowcasting tool based on the integration of lightning and radar data, which was developed to help the operational forecasters of the Meteorological Service of Catalonia to make decisions in the surveillance and warning of convective precipitation events. The method employs an object-oriented tracking procedure to identify, characterize and track thunderstorms in real time. Specifically, the object-oriented methodology considers four types of primary objects from different data and lightning data 
products (radar $1 \mathrm{~km}$ constant altitude plan position indicator (CAPPI) reflectivity composites, radar reflectivity volumetric data, cloud-to-ground lightning data and intra-cloud lightning data), which are combined into a higher level object, representing the thunderstorm. In addition, the authors test their procedure by considering several thunderstorms, which were observed during the summer of 2006, and analyze the results for three different thunderstorm stages (development, maturity and dissipation) and three types of thunderstorm intensities according to their maturity stage and cloudto-ground flash rate (weak, moderate and heavy).

Terradellas and Téllez (2010) analyze a case study over the Valencia region to illustrate strengths and weaknesses of using, for nowcasting purposes, near-real-time maps of vertically integrated water vapor (IWV) estimates based on ground-based observations of the microwave signals continuously broadcasted by the Global Navigation Satellite System (GNSS) satellites. These authors conclude that this product constitutes a promising tool for the operational forecasters, since it displays areas with strong moisture convergence and, therefore, potential convection triggering, causing alarm bells to ring long before any sign appears in other remote sensing systems. Nevertheless, they also point out the existence of false-alarm cases, when either the moisture convergence is too weak or the stratification is too stable to allow storm development.

The main conclusions and recommendations of this session were to a large extent similar to those of Sect. 5 for the remote sensing of storms, and therefore are not summarized here.

\section{Operational meteorological and hydrological forecasting}

End users of hydro-meteorological forecasts need to build and increase their reliance on the operational forecasting tools that are used daily to make decisions. This raises a question about the quantification of the uncertainty associated with forecasts. In addition, this uncertainty must be classified according to the type of hydro-meteorological event, since end users ask for reliable information on the predictability of the different types of hydro-meteorological events having high social impact. The problem can be addressed deterministically as well as probabilistically.

The deterministic, more traditional, approach aims at improving the reliability of the models by, for example, increasing the spatial and temporal resolutions, improving the physical representation of the processes, and assimilating the observations. Sensitivity computations and targeting data strategies are promising ways of improvement that need more tests and studies. Nevertheless, there is no doubt that a certain degree of uncertainty will remain in the operational forecasting, particularly for high social impact phenomena. The assessment of the residual uncertainty in the forecasts can be addressed probabilistically by resorting to ensemble predictions, rather than to single predictions. By using ensembles, it is indeed possible to formulate probabilistic forecasts properly and to determine the degree of uncertainty, as required by the end users. Thus, much work is being done in the development and testing of different kinds of ensemble predictions. Noteworthy is that statistical prediction is another complementary way to improve the forecasts and determine the uncertainty.

Verification of the forecasts is another important issue, both scientifically and for the end users. In this regard, it is worth mentioning that the improved models and the probabilistic forecasts require an effort to develop more appropriate verification methods. In any case, observation of phenomena plays a fundamental role and should be adequate both for data assimilation and for optimal reconstruction of a ground truth on which to test the models.

The papers by Garcies and Homar (2010) and by Peña et al. (2011) tackle the issue of improving deterministic forecasts. In this regard, one should consider that optimization of the observational strategies, so as to obtain a better representation of the atmosphere where the sensitivity to specific forecast aspects is at maximum, is a promising strategy to reduce NWP uncertainty. Thus, Garcies and Homar (2010) propose an optimized method for the determination of the ensemble sensitivity climatology of intense Mediterranean cyclones. In particular, the authors show that the proposed methodology is able to provide guidance on actual decisions regarding deployment and relocation of observational means.

In addition, knowledge of the synoptic patterns associated with extreme events is beneficial for reducing the uncertainty related to their operational forecasting. Indeed, this knowledge allows the expert, in the prediction phase, to focus on significant meteorological variables that are well represented by the models, and to derive from them information about other processes that have high social impact but are not satisfactorily resolved. In this context, databases of extreme events, built in the framework of projects such as MEDEX, are of paramount importance. Peña et al. (2011) analyze the strong-wind events of the MEDEX database and apply a clustering methodology, which allows singling out several discriminant mesoscale and synoptic-scale meteorological variables. Noteworthy is that the Meteorological Service of Catalonia is presently carrying out a study on how to use this methodology or the catalog obtained, to implement an analogous forecast system.

The paper by Vich and Romero (2010) deals with probabilistic forecast. The authors propose a superensemble technique to improve the prediction skills of high-impact precipitation and then test the method in western Mediterranean. The novelty of the superensemble method compared to traditional ensemble prediction systems (EPSs) is that, instead of weighting each EPS member equally, it takes into account the past performance of each member by assigning weights accordingly. Furthermore, the superensemble is constructed 
by varying the microphysical parameterizations of a single model instead of using different models. The authors find that their superensemble does not perform as expected when applied to rare and extreme events. This is largely attributed to the fact that the method needs to evaluate the behavior of individual members of the ensemble on the performance of similar events in the past, which is quite difficult for extreme and rare events.

Objective verification methods using reliable ground-truth observations are necessary to test the performance of deterministic and probabilistic operational NWP models. To a large extent, the problem is how to build a reliable ground truth from scattered and incomplete observations. Federico (2011) addresses the problem of evaluating the accuracy of the high-resolution $(2.5 \mathrm{~km}$ horizontal resolution) operational forecasts of minimum, average and maximum temperature, which are issued daily for the Calabria region (southern Italy) using the RAMS model, by means of an observation data set of ground-based point measurements taken by 87 thermometers having an average minimum distance of $10 \mathrm{~km}$.

\section{Air-sea interactions, ocean waves, and coastal surges}

For the first time in the Plinius Conferences history, many aspects directly involving the ocean have been joined in one topic. According to the call for papers, contributions on the effects of Mediterranean storms over the sea or on the role of the sea on the generation of Mediterranean storms were welcome. Among those are air-sea exchanges of heat and water, storm surges, seiches, effects of floods on the sea and the coastal system, coastal dynamics affected by wind storms, deep sea slides or beach dynamics, as well as on oceanographic conditions that may favor or hinder convective storms, extreme events of ocean dynamics or ocean sediments and impact of storms on aquatic ecosystems. In summary, the topic intended to cover a very wide range of events having air-sea interactions as the main player although, since limits are sometimes fuzzy, some contributions partially addressing air-sea interactions could also be found under other umbrellas terms such as climate change (i.e., Casas-Prat and Sierra, 2010).

During the conference, ten contributions were presented under this topic, covering the effects of storms on coastal systems and sediments, through wave generation, and effects of storms on ocean circulation, deep sediment dynamics and plankton life in the sea. Most of the contributions were based on direct observations of real phenomena, although there were some based on modeling and laboratory experiments. Heat and mass air-sea exchanges and their effects on atmospheric circulation or on hydrological cycles, although crucial for storm development, have been poorly addressed among the contributions presented. Therefore, at the round table held at the end of the sessions, it was concluded that the topic was successfully covered and would be kept for next Plinius Conferences to expand contributions on air-sea interactions.

The published contributions to the topic included four (three in the present volume and one in ADGEO) papers related to coastal hazards and three (one in the present volume and two in ADGEO) papers on the impact of storms within the sea.

Mendoza et al. (2011) present a statistical analysis on coastal storms based on wave energy. It is applied to the Catalan coast (NW Mediterranean) resulting in a 5-level intensity, which could be related to potential hazards. The results are then related to the presence of Mediterranean cyclones in synoptic analyses, although no direct correspondence on cyclone intensity with wave energy content is found. Bosom and Jiménez (2011) present a methodology to assess storm-induced coastal vulnerability based on a probabilistic approach whereby hazards time series are developed from existing storm data, separating the different induced processes: inundation and erosion. The Catalan coast is divided in different sectors defined in terms of the wave-climaterepresentative beach types. This method may allow coastal managers to decide the risks with regards to the function of the probability functions and the importance of the hinterland. Rasilla Álvarez and García Cordón (2011) present an assessment of the evolution of storminess along the northern coast of the Iberian Peninsula through the calculation of extreme total water levels based on both observed and hindcast data. Most of the events found correspond to a rough wave climate and moderate storm surges. An analysis of the longterm trends of oceanographic parameters and atmospheric circulation features shows that while local atmospheric conditions evolved towards less storminess, their impact has been balanced by the favorable exposure of that coast to the increasing frequency and strength of distant disturbances. Finally, morphological beach changes - submerged bar and shoreline position, configuration and shape of two Barcelona beaches - are analyzed from video monitoring by Ojeda et al. (2010) during 25 major storm events in the period 20012006. Beach responses to storms included shoreline advance or retreat, sandbar migration, configuration change and formation of megacusps. Examples of differential adaptation of both beaches to the same storm and some unexpected morphological responses could be found since the response of the beach to storm events was not straightforward because the specific morphodynamic configuration prior to the storm has to be considered in addition to the wave conditions.

Concerning the storms within the sea interior, Palanques et al. (2011) study the shelf-to-basin oceanic sediment transport at the southwestern end of the Gulf of Lion associated with storms. The paper presents simultaneous data about the effect of two severe E-SE storms, with significant wave heights $\geq 7 \mathrm{~m}$, on the shelf, the slope and the basin, during winter 2003-2004: one in December and the other in February. During both, coastal water was exported off-shelf 
producing strong near-bottom currents (up to $82 \mathrm{~cm} \mathrm{~s}^{-1}$ ) at the canyon head that resuspended sediment and increased the down-canyon sediment fluxes by several orders of magnitude. The suspended sediment flux increase in the canyon head was much larger during the February storm than during that of December because in February the storm was reinforced by dense shelf water cascading. Only few places in the world ocean are suitable for deep convection and shelf water cascading, and only under particular weather conditions that are able to trigger convective motion by increasing surface water density through freezing, cooling or evaporation. Salat et al. (2010) present a brief review of the response within the sea to those particular conditions in the NW Mediterranean. During deep convection episodes, the violent sinking and spreading of water parcels, which may reach the deep sea floor in few hours, are described in the paper as "hidden" Mediterranean storms, occurring under the sea surface. Finally, this group of papers dealing with the impacts of storms in the sea includes the contribution of Peters (2010) about the impact of the storms on the sea life, in particular on the plankton, via fluctuations of the pelagic environment. Storms are the drivers of extreme fluctuations that cascade down to small scales of turbulence, able to alter either nutrient availability to microscopic algae or swimming and mating behavior of motile plankton. In particular, storms may also have a role in the development and mitigation of harmful algal blooms, with economic and health consequences that are of societal concern.

\section{Rainfall-triggered landslides and coastal landslides/erosion}

While eight presentations (three of which are oral) were given at the conference within this topic, only one paper (Petrucci et al., 2010) was thereafter published in the ADGEO special issue. In addition, we summarize here the paper by De Lima et al. (2011) because it deals with aspects of great importance for the present topic, even though it is based on a solicited presentation that had been given within a different session (the one described in Sect. 8). Specifically, De Lima et al. (2011) present the laboratory setup, as well as the results of a series of experiments, aimed at simulating the ground effects of a rain cell moving at a constant speed over a soil flume. As stated by the authors, the purpose of the study is to contribute to the understanding of the differences in the discharge and grain-size distribution of the sediments that are generated on the slopes of a drainage area when rainstorms with different spatial and temporal rainfall characteristics are moving downstream or upstream. It is found that downstream moving storms produce more soil loss than upstream moving storms and that the evolution of sediment grain size depends on the direction of storm movement. In addition, the evolution patterns of mean grain-size distribution of transported sediments by overland flow are only partially consistent with the evolution of overland discharge. Generally, under higher discharge the transported sediment tends to be coarser, while for lower slopes the coarser particles tend to remain on the soil surface. Finally, downstream moving storms have greater peak discharges and can more easily mobilize particle sizes present on the soil surface.

The session devoted to landslides identified three main challenges for the future. The first one consists in the necessity to review the rainfall thresholds defined so far (mainly for local downpours) and redo the existing inventory of mass movements. The second one derives from the difficulty of distinguishing between different impacts when two or more natural hazards occur simultaneously. In effect, results show that some of the damages reported in the literature, which have been attributed to the effect of rainfall or floods in the Mediterranean mountains, must be associated instead with mass movements.

The third challenge refers to a usual problem in hazard assessment - the necessity of having complete inventories of both recent and historic mass movements. In this regard, the use of high-resolution aerial photographs and remote sensing data implemented within GIS platforms have become fundamental tools. The design of systems to forecast the occurrence of rainfall-induced landslides requires the assessment of the hazard level and the consideration of risk scenarios. It is also important to determine whether the expected damages and losses are mostly related to the landslide magnitude or to the vulnerability of the threatened elements. For this purpose, the availability of catalogs on the effects of historical landslides may be of great help. In this sense, Petrucci et al. (2010) propose a landslide damage assessment method called SAF (Support Analysis Framework), and apply it to the 2009 landslide event in Calabria (Italy).

Acknowledgements. We thank the EGU Council, the members of the scientific and the organizing committees, and the scientists who participated in the conference. Special thanks go to the many authors who submitted their papers to the joint special issues of NHESS and ADGEO. We are grateful to the reviewers for their helpful comments and suggestions on the individual manuscripts: their efforts have improved the quality of the two special issues. We also express our gratitude to Copernicus Meetings and Copernicus Publications for their professional support.

We gratefully acknowledge several institutions and projects for their generous financial and/or logistic support in organizing the conference: the European Geosciences Union, the European Science Foundation, the United Nations Office for Disaster Risk Reduction (UNISDR), the CIMA Research Foundation, the University of Barcelona, the Spanish Ministerio de Ciencia e Innovación, the Spanish Agencia Estatal de Meteorología, the Generalitat de Catalunya (Consell Assessor per al Desenvolupament Sostenible de la Generalitat de Catalunya, Servei Meteorològic de Catalunya, Direcció, General de Protecció Civil, Comissionat per a Universitats i Recerca del Departament d'Innovació, Universitats i Empresa), the Clavegueram de Barcelona (CLABSA) and the FLASH European 
project and the HyMeX, MedCLIVAR, MEDFRIEND and MEDEX projects.

We finally acknowledge our friends and colleagues Pinhas Alpert, Aristides Bartzokas, Pierluigi Claps, Jordi Corominas, Silvio Davolio, Efi Foufoula-Georgiou, Agustì Jansà, Vassiliki Kotroni, Konstantinos Lagouvardos, Bruce Malamud, Silas Michaelides, Efrat Morin, Colin Price, Romualdo Romero, Giorgio Roth, Franco Siccardi, Eric A. Smith, and Gregory J. Tripoli for their vital contribution in compiling the main conclusions of this conference, and Montserrat Llasat-Botija for her contribution to the success of the conference.

\section{References}

Altamura, M., Ferraris, L., Miozzo, D., Musso, L., and Siccardi, F.: The legal status of Uncertainty, Nat. Hazards Earth Syst. Sci., 11, 797-806, doi:10.5194/nhess-11-797-2011, 2011.

Amaro, J., Gayà, M., Aran, M., and Llasat, M. C.: Preliminary results of the Social Impact Research Group of MEDEX: the request database (2000-2002) of two Meteorological Services, Nat. Hazards Earth Syst. Sci., 10, 2643-2652, doi:10.5194/nhess-10-2643-2010, 2010.

Atencia, A., Rigo, T., Sairouni, A., Moré, J., Bech, J., Vilaclara, E., Cunillera, J., Llasat, M. C., and Garrote, L.: Improving QPF by blending techniques at the Meteorological Service of Catalonia, Nat. Hazards Earth Syst. Sci., 10, 1443-1455, doi:10.5194/nhess-10-1443-2010, 2010.

Balasch, J. C., Ruiz-Bellet, J. L., Tuset, J., and Martín de Oliva, J.: Reconstruction of the 1874 Santa Tecla's rainstorm in Western Catalonia (NE Spain) from flood marks and historical accounts, Nat. Hazards Earth Syst. Sci., 10, 2317-2325, doi:10.5194/nhess-10-2317-2010, 2010.

Bosom, E. and Jiménez, J. A.: Probabilistic coastal vulnerability assessment to storms at regional scale - application to Catalan beaches (NW Mediterranean), Nat. Hazards Earth Syst. Sci., 11, 475-484, doi:10.5194/nhess-11-475-2011, 2011.

Caloiero, T., Coscarelli, R., Ferrari, E., and Mancini, M.: Precipitation change in Southern Italy linked to global scale oscillation indexes, Nat. Hazards Earth Syst. Sci., 11, 1683-1694, doi:10.5194/nhess-11-1683-2011, 2011.

Camarasa Belmonte, A. M., Soriano García, J., and López-García, M. J.: The effect of observation timescales on the characterisation of extreme Mediterranean precipitation, Adv. Geosci., 26, 61-64, doi:10.5194/adgeo-26-61-2010, 2010.

Casas-Prat, M. and Sierra, J. P.: Trend analysis of wave storminess: wave direction and its impact on harbour agitation, Nat. Hazards Earth Syst. Sci., 10, 2327-2340, doi:10.5194/nhess-102327-2010, 2010.

de Lima, J. L. M. P., Dinis, P. A., Souza, C. S., de Lima, M. I. P., Cunha, P. P., Azevedo, J. M., Singh, V. P., and Abreu, J. M.: Patterns of grain-size temporal variation of sediment transported by overland flow associated with moving storms: interpreting soil flume experiments, Nat. Hazards Earth Syst. Sci., 11, 26052615, doi:10.5194/nhess-11-2605-2011, 2011.

de Lima, M. I. P., Carvalho, S. C. P., and de Lima, J. L. M. P.: Investigating annual and monthly trends in precipitation structure: an overview across Portugal, Nat. Hazards Earth Syst. Sci., 10, 2429-2440, doi:10.5194/nhess-10-2429-2010, 2010.
Dietrich, S., Casella, D., Di Paola, F., Formenton, M., Mugnai, A., and Sanò, P.: Lightning-based propagation of convective rain fields, Nat. Hazards Earth Syst. Sci., 11, 1571-1581, doi:10.5194/nhess-11-1571-2011, 2011.

Duffourg, F. and Ducrocq, V.: Origin of the moisture feeding the Heavy Precipitating Systems over Southeastern France, Nat. Hazards Earth Syst. Sci., 11, 1163-1178, doi:10.5194/nhess-111163-2011, 2011.

Federico, S.: Verification of surface minimum, mean, and maximum temperature forecasts in Calabria for summer 2008, Nat. Hazards Earth Syst. Sci., 11, 487-500, doi:10.5194/nhess-11-487-2011, 2011.

Garcies, L. and Homar, V.: An optimized ensemble sensitivity climatology of Mediterranean intense cyclones, Nat. Hazards Earth Syst. Sci., 10, 2441-2450, doi:10.5194/nhess-10-24412010, 2010.

Gayà, M., Llasat, M.-C., and Arús, J.: Tornadoes and waterspouts in Catalonia (1950-2009), Nat. Hazards Earth Syst. Sci., 11, 18751883, doi:10.5194/nhess-11-1875-2011, 2011.

Gómez, I., Pastor, F., and Estrela, M. J.: Sensitivity of a mesoscale model to different convective parameterization schemes in a heavy rain event, Nat. Hazards Earth Syst. Sci., 11, 343-357, doi:10.5194/nhess-11-343-2011, 2011.

Groppelli, B., Soncini, A., Bocchiola, D., and Rosso, R.: Evaluation of future hydrological cycle under climate change scenarios in a mesoscale Alpine watershed of Italy, Nat. Hazards Earth Syst. Sci., 11, 1769-1785, doi:10.5194/nhess-11-1769-2011, 2011.

Iacobellis, V., Gioia, A., Manfreda, S., and Fiorentino, M.: Flood quantiles estimation based on theoretically derived distributions: regional analysis in Southern Italy, Nat. Hazards Earth Syst. Sci., 11, 673-695, doi:10.5194/nhess-11-673-2011, 2011.

Katsafados, P., Mavromatidis, E., Papadopoulos, A., and Pytharoulis, I.: Numerical simulation of a deep Mediterranean storm and its sensitivity on sea surface temperature, Nat. Hazards Earth Syst. Sci., 11, 1233-1246, doi:10.5194/nhess-111233-2011, 2011.

Koletsis, I., Lagouvardos, K., Kotroni, V., and Bartzokas, A.: The interaction of northern wind flow with the complex topography of Crete Island - Part 2: Numerical study, Nat. Hazards Earth Syst. Sci., 10, 1115-1127, doi:10.5194/nhess-10-11152010, 2010.

Lambert, D., Mallet, M., Ducrocq, V., Dulac, F., Gheusi, F., and Kalthoff, N.: CORSiCA: a Mediterranean atmospheric and oceanographic observatory in Corsica within the framework of HyMeX and ChArMEx, Adv. Geosci., 26, 125-131, doi:10.5194/adgeo-26-125-2011, 2011.

Llasat, M. C. and Siccardi, F.: A reflection about the social and technological aspects in flood risk management - the case of the Italian Civil Protection, Nat. Hazards Earth Syst. Sci., 10, 109-119, doi:10.5194/nhess-10-109-2010, 2010.

Lara, A., Saurí, D., Ribas, A., and Pavón, D.: Social perceptions of floods and flood management in a Mediterranean area (Costa Brava, Spain), Nat. Hazards Earth Syst. Sci., 10, 2081-2091, doi:10.5194/nhess-10-2081-2010, 2010.

Llasat, M. C., Boni, G., Deidda, R., Mugnai, A., and Salatm J. (Eds.): 11th EGU Plinius Conference on Mediterranean Storms, Special Issue, Adv. Geosci., http://www.adv-geosci.net/ 26/index.html, 2010a. 
Llasat, M. C., Llasat-Botija, M., Rodriguez, A., and Lindbergh, S.: Flash floods in Catalonia: a recurrent situation, Adv. Geosci., 26, 105-111, doi:10.5194/adgeo-26-105-2010, 2010b.

Martín, M. L., Valero, F., Pascual, A., Morata, A., and Luna, M. Y.: Springtime connections between the large-scale sea-level pressure field and gust wind speed over Iberia and the Balearics, Nat. Hazards Earth Syst. Sci., 11, 191-203, doi:10.5194/nhess11-191-2011, 2011.

Mascaro, G., Vivoni, E. R., and Deidda, R.: Physical controls on the scale-dependence of ensemble streamflow forecast dispersion, Nat. Hazards Earth Syst. Sci., 10, 1605-1615, doi:10.5194/nhess-10-1605-2010, 2010.

Mazarakis, N., Kotroni, V., Lagouvardos, K., Argiriou, A. A., and Anderson, C. J.: The sensitivity of warm period precipitation forecasts to various modifications of the Kain-Fritsch Convective Parameterization scheme, Nat. Hazards Earth Syst. Sci., 11, 1327-1339, doi:10.5194/nhess-11-1327-2011, 2011.

Mendoza, E. T., Jimenez, J. A., and Mateo, J.: A coastal storms intensity scale for the Catalan sea (NW Mediterranean), Nat. Hazards Earth Syst. Sci., 11, 2453-2462, doi:10.5194/nhess-112453-2011, 2011.

Montesarchio, V., Ridolfi, E., Russo, F., and Napolitano, F.: Rainfall threshold definition using an entropy decision approach and radar data, Nat. Hazards Earth Syst. Sci., 11, 2061-2074, doi:10.5194/nhess-11-2061-2011, 2011.

Mugnai, A., Guzzetti, F., and Roth, G.: Outcomes of the 9th EGU Plinius Conference on Mediterranean Storms (2007), Nat. Hazards Earth Syst. Sci., 10, 875-879, doi:10.5194/nhess-10-8752010, 2010.

Müller, M. and Kaspar, M.: Association between anomalies of moisture flux and extreme runoff events in the southeastern Alps, Nat. Hazards Earth Syst. Sci., 11, 915-920, doi:10.5194/nhess-11-915-2011, 2011.

Neppel, L., Pujol, N., and Sabatier, R.: A multivariate regional test for detection of trends in extreme rainfall: the case of extreme daily rainfall in the French Mediterranean area, Adv. Geosci., 26, 145-148, doi:10.5194/adgeo-26-145-2011, 2011.

Ojeda, E., Guillén, J., and Ribas, F.: The morphodynamic responses of artificial embayed beaches to storm events, Adv. Geosci., 26, 99-103, doi:10.5194/adgeo-26-99-2010, 2010.

Olcina Cantos, J., Hernández Hernández, M., Rico Amorós, A. M., and Martínez Ibarra, E.: Increased risk of flooding on the coast of Alicante (Region of Valencia, Spain), Nat. Hazards Earth Syst. Sci., 10, 2229-2234, doi:10.5194/nhess-10-2229-2010, 2010.

Ortego, M. I., Gibergans-Báguena, J., Tolosana-Delgado, R., Egozcue, J. J., and Llasat, M. C.: Bayesian trend analysis for daily rainfall series of Barcelona, Adv. Geosci., 26, 71-76, doi:10.5194/adgeo-26-71-2010, 2010.

Palanques, A., Puig, P., Guillén, J., Durrieu de Madron, X., Latasa, M., Scharek, R., and Martin, J.: Effects of storm events on the shelf-to-basin sediment transport in the southwestern end of the Gulf of Lions (Northwestern Mediterranean), Nat. Hazards Earth Syst. Sci., 11, 843-850, doi:10.5194/nhess-11-843-2011, 2011.
Pelosini, R., Bovo, S., and Cordola, M.: Lessons learnt from the snow emergency management of winter season 2008-2009 in Piemonte, Adv. Geosci., 26, 149-153, doi:10.5194/adgeo-26149-2011, 2011.

Peña, J. C., Aran, M., Cunillera, J., and Amaro, J.: Atmospheric circulation patterns associated with strong wind events in Catalonia, Nat. Hazards Earth Syst. Sci., 11, 145-155, doi:10.5194/nhess11-145-2011, 2011.

Peters, F.: On some relationships between storms and plankton dynamics, Adv. Geosci., 26, 33-38, doi:10.5194/adgeo-26-332010, 2010.

Petrucci, O., Pasqua, A. A., and Gullà, G.: Landslide damage assessment using the Support Analysis Framework (SAF): the 2009 landsliding event in Calabria (Italy), Adv. Geosci., 26, 1317, doi:10.5194/adgeo-26-13-2010, 2010.

Portoghese, I., Bruno, E., Guyennon, N., and Iacobellis, V.: Stochastic bias-correction of daily rainfall scenarios for hydrological applications, Nat. Hazards Earth Syst. Sci., 11, 24972509, doi:10.5194/nhess-11-2497-2011, 2011.

Rasilla Álvarez, D. F. and García Codron, J. C.: Evolution of extreme Total Water Levels along the northern coast of the Iberian Peninsula, Nat. Hazards Earth Syst. Sci., 11, 613-625, doi:10.5194/nhess-11-613-2011, 2011.

Rianna, M., Russo, F., and Napolitano, F.: Stochastic index model for intermittent regimes: from preliminary analysis to regionalisation, Nat. Hazards Earth Syst. Sci., 11, 1189-1203, doi:10.5194/nhess-11-1189-2011, 2011.

Rigo, T., Pineda, N., and Bech, J.: Analysis of warm season thunderstorms using an object-oriented tracking method based on radar and total lightning data, Nat. Hazards Earth Syst. Sci., 10, 18811893, doi:10.5194/nhess-10-1881-2010, 2010.

Roux, H., Labat, D., Garambois, P.-A., Maubourguet, M.-M., Chorda, J., and Dartus, D.: A physically-based parsimonious hydrological model for flash floods in Mediterranean catchments, Nat. Hazards Earth Syst. Sci., 11, 2567-2582, doi:10.5194/nhess-11-2567-2011, 2011.

Salat, J., Puig, P., and Latasa, M.: Violent storms within the Sea: dense water formation episodes in the NW Mediterranean, Adv. Geosci., 26, 53-59, doi:10.5194/adgeo-26-53-2010, 2010.

Sirangelo, B., Ferrari, E., and De Luca, D. L.: Occurrence analysis of daily rainfalls through non-homogeneous Poissonian processes, Nat. Hazards Earth Syst. Sci., 11, 1657-1668, doi:10.5194/nhess-11-1657-2011, 2011.

Terradellas, E. and Téllez, B.: The use of products from groundbased GNSS observations in meteorological nowcasting, Adv. Geosci., 26, 77-82, doi:10.5194/adgeo-26-77-2010, 2010.

Terranova, O. G. and Iaquinta, P.: Temporal properties of rainfall events in Calabria (southern Italy), Nat. Hazards Earth Syst. Sci., 11, 751-757, doi:10.5194/nhess-11-751-2011, 2011.

Vich, M. and Romero, R.: Multiphysics superensemble forecast applied to Mediterranean heavy precipitation situations, Nat. Hazards Earth Syst. Sci., 10, 2371-2377, doi:10.5194/nhess-102371-2010, 2010. 